\title{
A Wood Preservative Based on Commercial Silica Nanodispersions and Boric Acid against Fungal Decay through Laboratory and Field Tests
}

\author{
Sabrina Palanti*, Elisabetta Feci \\ CNR IVALSA, Istituto per la Valorizzazione del Legno e delle Specie Arboree, Sesto Fiorentino, Italy \\ Email: "palanti@ivalsa.cnr.it
}

Received December $18^{\text {th }}$, 2012; revised February $14^{\text {th }}$, 2013; accepted March $6^{\text {th }}, 2013$

Copyright ( 2013 Sabrina Palanti, Elisabetta Feci. This is an open access article distributed under the Creative Commons Attribution License, which permits unrestricted use, distribution, and reproduction in any medium, provided the original work is properly cited.

\begin{abstract}
The paper is based on the development of a wood preservative without metal salts to be used in use classes 3 and 4 (EN 335), eco-friendly and harmless to humans and animals. Boric acid was used as a biocide, due to its effectiveness against fungi and insects. It is also known to be easily leached from wood exposed to weather action. Colloidal silica was therefore added in the formulations to guarantee the fixation of boric acid to wood. The different formulations were tested for the protective efficacy against decay fungi through laboratory tests (EN 113) and field trials (EN 252). The results were promising, especially those concerning boron fixation and efficacy against decay fungi through laboratory tests, where some formulations and retentions gave a durability class 1 (very durable) according to EN 350-1. The fourth evaluation, after 50 months of field trials showed only a slight difference between the treated samples and controls.
\end{abstract}

Keywords: Basidiomycetes; Boric Acid; Colloidal Silica; Wood Durability; Field Test

\section{Introduction}

Protecting wood from biotic decay is a necessity and also an obligation for producers of wooden artefacts. The wood preservatives have to ensure the resistance of wood to biotic agents for a long time in service conditions, so it is important that active ingredients are permanently fixed to the walls of wood cells.

Currently the most used products for use classes 3 and 4 (EN 335) are formulations based on copper salts and other co-formulates as azoles, organic compounds and boron (Forest Products Laboratory, 2010). The disadvantage of these compounds is due to utilization of metal compounds and to the facility of leaching them away when utilized in outdoor conditions.

Boric acid is a substance effective against fungi and insects xylophages and is also non-toxic to humans and the environment if used under the limit indicated in Biocides Directive 98/8/EC. Nevertheless, this substance alone cannot be applied to wood exposed to the atmospheric agents because it is easily washed away into the ground. The recent classification of boric acid and borates as toxic to the human reproduction, category 1B (EU Regulation 790/2009) means that they fall within the scope of the measures of risk reduction provided by the $\mathrm{REACH}$ regulation (licensing procedures and restrictions). The justification for the use of boric acid is linked to the fact that the repro-toxic effect occurs at a threshold concentration of $5.5 \%$. Below this threshold this compound is considered safe.

There are some compounds that form complexes with boric

*Corresponding author. acid and thereby lock it when introduced into the wood. Their employment in the industry is hampered by some technical difficulties during the preparation.

In order to develop an environmentally friendly preservative, this research work has had as its aim the development of wood preservative formulations based on boric acid and colloidal silica nanodispersions with different weight percentagesin $\mathrm{SiO}_{2}$ and size particles.

Silicic acid in combination with boric acid has been shown to be effective against wood decay fungi and termites, when applied to wood with vacuum-pressure impregnation cycle (Yamaguchi, 2001, 2003, 2005).

The theorized mechanism for the attachment of boron is due to the atomic structure of the colloidal silica performed by the compound $\mathrm{SiO}_{4}$. This compound has tetrahedral structure with the silicon atom in the centre. Each molecule of silica is combined with others so that each silicon atom has available three oxygen atoms of the tetrahedron. It is assumed that the boron atoms, which have a structure similar to $\mathrm{Si}$, may replace one atom into the tetrahedron (Ueda, 1993). Once heated, the mixture, boric acid and colloidal silica, takes a glassy appearance, blocking the vessels of wood, with flame-retardant property. In this case, the attachment of boron is due to the fact that boron atoms are replaced with those of silicon in the colloidal solution, once introduced into the wood by impregnation with vacuumpressure cycle and hence is permanently blocked by the gelling of colloidal silica after heating wood.

In this research boric acid was added as the active biocidea- 
gainst fungi.

The evaluations of the experimental formulations were therefore concerned with:

- Antifungal efficacy through laboratory tests;

- Fixation of boric acid into the wood;

- Antifungal efficacy through in field tests.

\section{Material and Methods}

\section{Treatments Based on Colloidal Silica and Boric Acid}

The treatments were based on boric acid and nanodispersions of colloidal silica.

Some commercial silica dispersions (Eka Chemicals AB and Nissan Chemical Industrex) of different weight percentage and different silica nanoparticles size were utilized.

EN 113 wood blocks and EN 252 stakes were treated with a formulation based on $20.7 \%$ of a colloidal dispersion of silica particles in slightly alkaline water, Bindzil ${ }^{\circledR}$ CC 30 (Eka Chemicals $\mathrm{AB}$ ) and $2.3 \%$ boric acid, technical grade.

Previous experiments to evaluate the fixation of boric acid into the wood were performed according to EN 84 on wood blocks treated with a formulation based on $20.5 \%$ colloidal silica (Snowtex C, Nissan Chemical) and 2.59\% boric acid.

The treatment emulsions were impregnated into the wood according to the following cycle: vacuum $0.7 \mathrm{kPa}$ for $30 \mathrm{~min}-$ utes, pressure $200 \mathrm{kPa}$ for 5 minutes, $400 \mathrm{kPa}$ for 5 minutes, $600 \mathrm{kPa}$ for 5 minutes and $700 \mathrm{kPa}$ for 30 minutes.

Retentions were calculated as amount of dry residual expressed in kilograms per cubic meter of wood.

\section{Wood Species}

The wood samples were derived from Scots pine (Pinus sylvestries L.) sapwood.

\section{Laboratory Decay Test (EN 113: 1996)}

Laboratory decay test were carried out in accordance with European standard EN 113, 1996.

Treated wood samples, dimensions: $(50 \pm 0.5) \times(25 \pm 0.5) \times$ $(15 \pm 0.5) \mathrm{mm}^{3}$, were exposed to fungal attack for 16 weeks in a conditioning room $\left(22 \pm 2^{\circ} \mathrm{C}, 70 \pm 5 \% \mathrm{RH}\right)$. The test requires the inclusion of three certified fungi, one obligatory-the brown rot fungus Coniophora puteana (Schumacher ex Fries) Karsten (strain BAM Ebw.15) and the two additional brown rot fungi Poria placenta (Fries) Cooke sensu J. Eriksson (strain FPRL280) and Gloeophyllum trabeum (Persoon ex Fries) Murrill (strain BAM ebw.109). For each fungus, ten treated samples were tested. A treated sample was placed with an untreated reference one in a Kolle flask, containing one of the above described brown rot fungus grown on $20 \mathrm{ml}$ of $4 \%$ malt and $2.5 \%$ agar medium. A modification of the EN 113 (1996), that consists in the division into two parts of the mycelium inside the Kolle flask before the exposure to wood samples (Figure 1), so that the fungal strain virulence (tested on control samples) was prevented from inhibition by the preservative washed away from the treated samples. In fact, the inhibition of the fungus by boric acid washed away from treated sample against control specimens, as resulted from preliminary tests, did not allow for demonstrating the effectiveness of the product, according to the criteria of the standard. This effect due to the leaching of boron from non-leached treated samples has been observed in preliminary

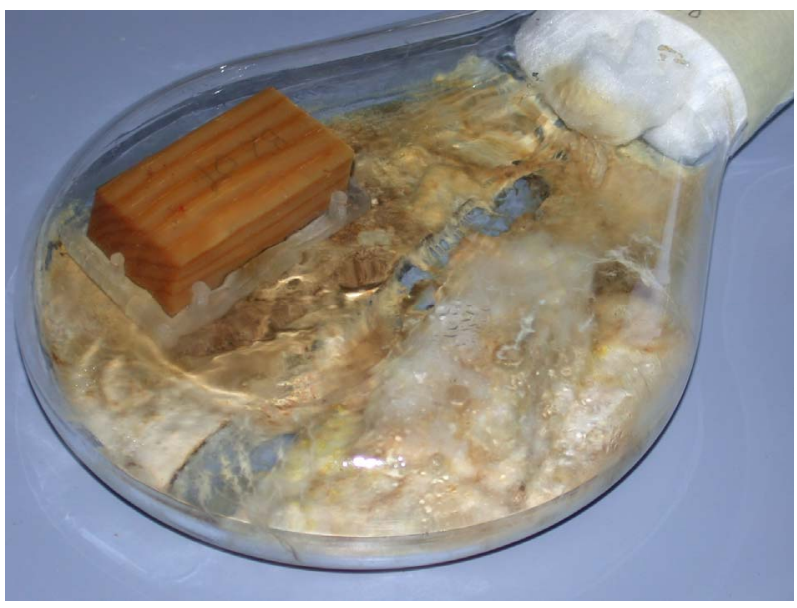

Figure 1.

Mycelium within the Kolle flask, divided into portions.

non-published experiments of the authors.

Furthermore, six treated wood blocks (called in EN 113 (1996) check blocks) were put in contact with culture medium without fungal strains for the determination of the correction coefficient, which was used to calculate the possible mass loss due to factors different from fungal decay. Another set of six untreated wood specimens for each tested fungus was used to check for virulence of fungus.

The resistance against fungi was evaluated through the measurement of the percent mass loss of wood, which was calculated for each individual block as the difference between the dry mass before the impregnation process and after the fungal exposure, corrected by correction coefficient. A minimum of $20 \%$ mass loss on control (untreated) samples was required for the test to be valid.

\section{Leaching Tests (EN 84:1997)}

Treated wood samples, dimensions $(5 \pm 0.1) \times(15 \pm 0.1) \times$ (30 \pm 0.5$) \mathrm{mm}^{3}$, were subjected to leaching according to EN 84, 1997. This standard describes an accelerated ageing test of specimens treated with a preservative for simulating the service conditions, in particular exposure to rainfall. The cycle consisted of an initial $4 \mathrm{kPa}$ vacuum-atmospheric pressure cycle with distilled water. Then, wood specimens were maintained in water (ratio of water to wood 5:1) for 14 days with 9 water changes, and then conditioned to constant mass.

The leaching waters were subjected to analysis by ICP (Inductive Coupled Plasma) for the determination of boron.

The percentage of residual boric acid in the wood was calculated by the difference with the amount obtained from the analysis on initial formulation, where its content is $100 \%$.

\section{Field Test (EN 252: 1989)}

In ground test was performed in accordance with EN 252, 1989. This standard describes a method for the determination of efficacy of preservative applied by impregnation plant in ground condition. The method is also utilized for the determination of natural durability of wood in ground condition (EN 350, 1994).

The test sites were respectively situated in Cesa, Arezzo (lat $43.3^{\circ} \mathrm{N}$; long $11.8^{\circ} \mathrm{E}$ ), and Follonica, Grosseto (lat $42.9^{\circ} \mathrm{N}$; long 
$\left.10.8^{\circ} \mathrm{E}\right)$, Italy.

Duration of the test is a minimum 5-years period or until the stakes fail. The wood samples were placed in situ in October 2007 and in this paper the fourth evaluation was reported, after respectively 54 and 50 months for Cesa and Follonica.

Stakes, dimensions $(500 \pm 1) \times(50 \pm 3) \times(25 \pm 0.3) \mathrm{mm}^{3}$, were cut and conditioned before being impregnated and conditioned to constant mass.

The stakes were placed vertically in the soil leaving half of length exposed. Untreated stakes were also buried up to half their length in the soil test site.

Ten replicates for treatment and reference controls were utilized.

The fungal decay was evaluated in the area in ground contact. Annual inspections were carried out by giving a light blow to the upper part of each stake followed by removal from the ground. Surface examination was performed with an awl. The fungal decay was evaluated on the basis of the depth of fungal softening and extension area according to a specific rating system: 0 sound, 1 slight attack, 2 moderate attack, 3 severe attack and 4 failure (stake breaks in the ground after blowing). The evaluation was performed in accordance with guideline for EN 252 of Nordic Wood Preservation Council (Borsholt \& Henriksen, 1992). After evaluation, each stake was re-installed in the original position.

As preservative reference, ten stakes treated with Impralith KDS (Rütger Organics $\mathrm{GmbH}$ ), with a retention use class 4 (EN 599-1, 2009), were used. As control reference ten untreated were utilized.

Conferred durability classes were calculated according to EN 350-1, 1994.

\section{Results}

\section{Retention}

The impregnation of EN 113 wood blocks gave the followings results: $201.37 \pm 11.54 \mathrm{~kg} / \mathrm{m}^{3}(\mathrm{~N}=36)$. Impregnation of wood mini-blocks for the leaching test gave as result $194.48 \pm$ $4.03 \mathrm{~kg} / \mathrm{m}^{3}(\mathrm{~N}=10)$.

The impregnation of EN 252 wood stakesgave the followings results: $55.6 \pm 15.50 \mathrm{~kg} / \mathrm{m}^{3}(\mathrm{~N}=20)$. The stakes impregnated with reference preservative Impralith KDS had an average retention of $8.65 \pm 1.26 \mathrm{~kg} / \mathrm{m}^{3}(\mathrm{~N}=25)$.

\section{Decay Tests}

Virulence of fungal strains confirmed the validity of the test (mass loss of untreated samples more than 20\%).

Results of antifungal efficacy were expressed as average mass loss and standard deviation of treated samples with the formulation tested (Table 1). All reference wood blocks lost more than $20 \%$ mass, the minimum value required for the validity of the test according to standard EN 113.

The mean mass loss due to the check block was $16.11 \% \pm$ $3.23 \%$, this results was due to the leaching of boron from wood blocks into the medium.

\section{Leaching Test}

Results of leaching are reported in Figure 2, where the percentages of residual boric acid for the formulation impregnated into the wood are graphed. Number 0 corresponds to the

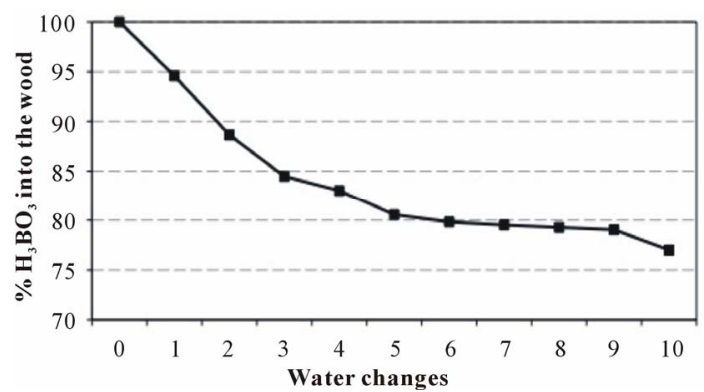

Figure 2.

Residual percentage of boric acid into the wood with respect to the initial concentration. The starting point (Water change number 0 ) represents the initial formulation and the corresponding boric acid content is $100 \%$.

Table 1.

EN 113, decay test results; sd = standard deviation, $\mathrm{N}=$ number of samples.

\begin{tabular}{ccc}
\hline Fungus & $\begin{array}{c}\text { Wood blocks treated \% } \\
\text { mass loss average (sd) } \\
\mathbf{N}=\mathbf{1 0}\end{array}$ & $\begin{array}{c}\text { Wood blocks references } \\
\text { average \% mass loss } \\
\mathbf{N}=\mathbf{1 0}\end{array}$ \\
\hline C. puteana & $6.87(1.42)$ & $59.16(3.92)$ \\
P. placenta & $6.65(0.66)$ & $48.25(5.16)$ \\
G. trabeum & $6.27(1.02)$ & $30.87(5.45)$ \\
\hline
\end{tabular}

amount determined by ICP analysis in the impregnation solution, which was assumed to be entirely and homogenously penetrated into wood. This assumption can be considered realistic because at the concentration of $2.3 \%$ the boric acid is well solved into the water of silica dispersion.

The ICP boron analysis has shown a decreasing presence of the active ingredient in consecutively obtained leaching waters. The loss of boric acid was $23.0 \%$. Compared to the amount present in the initial solution, boric acid decreased from $2.59 \%$ to $1.99 \%$.

\section{Field Test (EN 252)}

Annual evaluations on stakes from the two experimental fields are shown in Table 2.

For each evaluation, the average decay values of the stakes treated with colloidal silica-boric acid formulation, the stakes treated with the reference wood preservative and the untreated stakes are reported.

\section{Discussion}

The different average retentions obtained for each test samples group were probably due to different size of wood specimens. It has been remarked that the different dimensions of specimens utilized in different standardized tests could have been influenced the final retention of formulations tested: the smaller the wood samples, the higher were the retentions, (e.g. EN 113, EN 84); the lower performance was obtained with the EN 252 stakes.

The expression of EN 113 decay test results as conferred durability of wood according to EN 350-1 (1994) led to durability class 1 -very durable, with an expected service life exceeding 25 years (Eaton and Hale, 1993).

In Table 1, the masses losses indicate that the treatment gave 
Table 2.

EN 252 Decay results.

\begin{tabular}{|c|c|c|c|c|}
\hline \multirow{2}{*}{ Place: Cesa } & $\begin{array}{l}15^{\text {th }} \text { month by } \\
\text { installation }\end{array}$ & $\begin{array}{l}29^{\text {th }} \text { month by } \\
\text { installation }\end{array}$ & $\begin{array}{l}40^{\text {th }} \text { month by } \\
\text { installation }\end{array}$ & $\begin{array}{l}54^{\text {th }} \text { month by } \\
\text { installation }\end{array}$ \\
\hline & \multicolumn{4}{|c|}{ Average decay } \\
\hline CC30 colloidal silica and boric acid & 0.33 & 1.33 & 2.67 & 3.27 \\
\hline Impralith KDS & 0.15 & 0.69 & 1.46 & 1.46 \\
\hline Untreated control & 0.60 & 2.40 & 2.70 & 3.00 \\
\hline Place: Follonica & $\begin{array}{l}13^{\text {th }} \text { month by } \\
\text { installation }\end{array}$ & $\begin{array}{l}24^{\text {th }} \text { month by } \\
\text { installation }\end{array}$ & $\begin{array}{l}36^{\text {th }} \text { month by } \\
\text { installation }\end{array}$ & $\begin{array}{l}50^{\text {th }} \text { month by } \\
\text { installation }\end{array}$ \\
\hline CC30 colloidal silica and boric acid & 0.30 & 2.30 & 3.60 & 4.00 \\
\hline Impralith KDS & 0 & 0 & 0.30 & 0.70 \\
\hline Untreated control & 2.5 & 4 & - & 3.8 (the $2^{\text {nd }}$ series) \\
\hline
\end{tabular}

protection against fungi with respect to untreated wood. Never theless, this preservative was not efficacy in accordance with the criteria of validity of EN 113 (1996), where is stated that a wood preservative is efficacy when its mass loss is below than $3 \%$.

The amount of boric acid leached was probably an exceeding part that did not participate in the complex formation and consequently did not remain fixed in the wood. If it is assumed that after the impregnation the concentration of boric acid into the wood was the same as in the initial formulation, the fixation of boric acid was more than $75 \%$. These results support the theory on the interaction between silica and boric acid and demonstrate the ability of silica to block the active ingredient in the wood.

Evaluation of EN 252 in two sites gave very similar results with the retention tested $55.6 \mathrm{~kg} / \mathrm{m}^{3}$.

In Cesa, an agricultural soil near Arezzo, during the fourth evaluation, the colloidal silica-boric acid treated stakes had an higher decay (3.27) than the untreated control stakes (3.00). During the first two evaluations there was a gap between the two sets of stakes, infact the decay grade were respectively 1.33 and 2.40 for silica-boric acid and untreated stakes, suggesting the treatment was better than untreated wood. During the third year this gap was plugged, the two series scoring the same grade of decay (2.67 and 2.70).

On the contrary, in Follonica, an agricultural soil close to the coast, the higher decay grade was reached by control stakes after 50 months from beginning and another series of control stakes has been installed. At the fourth evaluation (after 50 months) the decay grade of silica-boric acid was 4.00. In this case also there was not a substantial difference between treated and untreated specimens, suggesting the treatment is no better than untreated controls.

In both sites the copper salt wood preservative gave better results, reaching respectively 1.46 in Cesa and 0.70 in Follonica.

The fungi, principally white rots, found in Follonica, resulted more aggressive versus untreated and colloidal silica-boric acidtreated stakes with respect to those found in Cesa.

\section{Conclusion}

The formulations colloidal silica-boric acid tested in this work have been very successful at retention $201 \mathrm{~kg} / \mathrm{m}^{3}$ and $194 \mathrm{~kg} / \mathrm{m}^{3}$ respectively in terms of resistance to fungal decay through laboratory testand with regard to fixation into the timber.
The results obtained in EN 252 field test with the lower retention, $55 \mathrm{~kg} / \mathrm{m}^{3}$, support the idea that this retention value could be used in use class 3 , not in contact with the ground, because this service condition is considered to severe, reaching a very high decay grade only after 50 - 54 months.

\section{Acknowledgements}

The authors thank the Regional Agency for Agriculture Developing and Innovation (ARSIA), TLF srl, Arezzo that supported this research and Mrs. Anna Maria Torniai from CNR Trees and Timber Institute who helped with fungi cultures.

\section{REFERENCES}

Borksholt, E., \& Henriksen, H. K. (1992). Guideline for EN 252: Field test method for determining the relative protective effectiveness of wood preservatives in ground contact NWPC. Information No. 23/90 ISSN 0358-707X.

(1998). Directive 98/8/EC of the European Parliament and of the Council of 16 February 1998 concerning the placing of biocidal products on the market.

EN 252 (1989). Field test method for determining the relative protective effectiveness of a wood preservative in ground contact.

EN 84 (1997). Wood preservatives-Accelerated ageing of treated wood prior to biological testing-Leaching procedure.

EN 113 (1996). Wood preservatives-Test method for determining the protective effectiveness against wood destroying basidiomycetesDetermination of the toxic values.

EN 335 (2006). Durability of wood and wood-based products-Definition of use classes-Part 1: General.

EN 350:1 (1994). Durability of wood and-based products. Natural durability of solid wood. Guide to the principles of testing and classification of thenatural durability of wood.

EN 599-1 (2009). Durability of wood and wood-based products-Efficacy of preventive wood preservatives as determined by biological tests-Part 1: Specification according to use class.

European Commission (2009). Commission Regulation (EC) No 790/ 2009 of 10 August 2009 amending, for the purposes of its adaptation to technical and scientific progress. Regulation (EC) No 1272/2008 of the European Parliament and of the Council on classification, labelling and packaging of substances and mixtures.

Eaton, R. A., \& Hale, M. D. (1993). Wood: Decay, pests, and protection. London: Chapman and Hall.

Forest Product Laboratory (2010). Wood handbook-Wood as an engineering material. General Technical Report FPL-GTR-190. Madison, WI: US Department of Agriculture, Forest Service, Forest Products Laboratory, 508 p.

Yamaguchi, H. (2001). Silicic acid-boric acid complexes as wood pre- 


\section{S. PALANTI, E. FECI}

servatives, IRG/WP01/30273.

Yamaguchi, H. (2003). Silicic acid: Boric acid complexes as wood preservatives. Wood Science and Technology, 37, 287-297.

doi:10.1007/s00226-003-0190-8

Yamaguchi, H. (2005). Silicic acid-boric acid complexes as ecologi- cally friendly wood preservatives. Forest Products Journal, 55, 8892.

Ueda, S. (1993). Jkken kagaku kouza (in Japonese, text of experimenthal chemistry) (16) (4th ed.). Tokyo: Maruzen Co. Ltd., 588. 